\title{
Optimize nucleot(s)ide analogues' to prevent hepatocellular carcinoma in patients with chronic hepatitis B: a lesson from real-world evidence
}

\author{
Jihye Lim, Jonggi Choi \\ Department of Gastroenterology, Liver Center, Asan Medical Center, University of Ulsan College of Medicine, Seoul 05505, \\ South Korea. \\ Correspondence to: Jonggi Choi, MD, PhD, Assistant Professor, Department of Gastroenterology, Asan Medical Center, \\ University of Ulsan College of Medicine 88 Olympic-ro 43-gil, Songpa-gu, Seoul 05505, South Korea. \\ E-mail: j.choi@amc.seoul.kr
}

How to cite this article: Lim J, Choi J. Optimize nucleot(s)ide analogues' to prevent hepatocellular carcinoma in patients with chronic hepatitis B: a lesson from real-world evidence. Hepatoma Res 2021;7:21.

http://dx.doi.org/10.20517/2394-5079.2020.138

Received: 30 Oct 2020 First Decision: 18 Jan 2021 Revised: 23 Jan 2021 Accepted: 2 Feb 2021 Published: 9 Mar 2021

Academic Editors: Antonio Bertoletti, Hong Tu Copy Editor: Yue-Yue Zhang Production Editor: Xi-Jun Chen

\begin{abstract}
The goal of antiviral treatment for chronic hepatitis B (CHB) is to reduce the risk of liver-related complications, including liver cirrhosis, hepatic decompensation, and hepatocellular carcinoma (HCC). It is not possible to eliminate hepatitis B virus from the host with currently available antiviral treatments; hence, a realistic goal is to decrease the risk of HCC as much as possible with an appropriate and timely antiviral treatment. For the past decades, real-world evidence has enlarged the field of $\mathrm{CHB}$ research. Presently, there is mounting evidence that randomized clinical trials are not technically and ethically possible to conduct. In this review, we focus on secondary prevention by antiviral treatment in patients with $\mathrm{CHB}$, mainly based on real-world evidence.
\end{abstract}

Keywords: Hepatitis B virus, hepatocellular carcinoma, antiviral agent

\section{INTRODUCTION}

Hepatitis B virus (HBV) infection is a major global health problem that causes life-threatening liver diseases, including hepatocellular carcinoma (HCC), cirrhosis, and end-stage liver disease. Globally, 292 million people are infected with HBV, and about 1.0 million people die annually from HBV-related

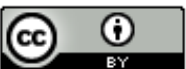

(C) The Author(s) 2021. Open Access This article is licensed under a Creative Commons Attribution 4.0 International License (https://creativecommons.org/licenses/by/4.0/), which permits unrestricted use sharing, adaptation, distribution and reproduction in any medium or format, for any purpose, even commercially, as long as you give appropriate credit to the original author(s) and the source, provide a link to the Creative Commons license, and indicate if changes were made.

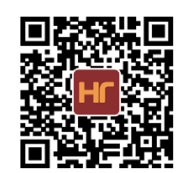


liver diseases, with an increasing trend ${ }^{[1,2]}$. Moreover, HBV infection causes more than $50 \%$ of HCC cases worldwide $^{[3]}$. The incidence of HBV-associated HCC varies geographically, depending on regional exposure to risk factors and the availability of healthcare resources ${ }^{[2,4]}$. Most HCC cases occur in East Asia and subSaharan Africa, where viral hepatitis is an endemic ${ }^{[5]}$. The prevalence of HBV infection has been decreasing since the successful introduction of HBV vaccination programs, which are the primary prevention methods for HCC. However, in many countries, the overall clinical burden of HCC is still growing.

Three preventive measures may reduce HBV-related HCC development. Primary preventions may be achieved by vaccination, change in behavioral patterns, and prevention of mother-to-child-transmission. Secondary prevention includes effective antiviral treatment against the development of HBV-related HCC and surveillance measures to detect early stage of HCC in those infected by HBV. Tertiary prevention is an effort to reduce the recurrence of HBV-related HCC in patients who have been successfully treated for HCC.

Currently, in the field of chronic hepatitis B (CHB), there is much interest in real-world evidence (RWE) that complements the knowledge gained from traditional clinical trials and provides important information about uncommon events, long-term clinical outcomes such as HCC, comparative treatment effectiveness, disease burden, and many more topics. For the past decade, progress in research design and advancements in statistical methodology have allowed the widespread adoption of RWE in clinical CHB research.

In this context, the aims of the present review are to (1) outline the secondary prevention of HBV-related HCC by nucleos(t)ide analogues (NUCs), with a specific focus on RWE; and (2) suggest possible strategies to further reduce the risk of HCC in patients with $\mathrm{CHB}$.

\section{HEPATOCELLULAR CARCINOMA DEVELOPMENT IN PATIENTS WITH CHRONIC HEPATITIS B}

HBV contributes to hepatocarcinogenesis via three mechanisms. The first involves chronic inflammation and hepatocyte regeneration due to persistent and sustained HBV replication. During this repetitive process, DNA mutation causes carcinogenesis ${ }^{[6]}$. Persistent and uncontrolled HBV replication is associated with an increased risk of HCC. One large-scale, untreated cohort study of more than 3,000 patients with CHB clearly showed a dose - response relationship between the serum HBV DNA level and the incremental risk of $\mathrm{HCC}^{[7]}$. In a long-term follow-up of the same cohort, persistently high viral load was associated with a higher rate of HCC than sustained low viral load ${ }^{[8]}$. Another study showed that serum hepatitis B surface antigen (HBsAg) level was also associated with HCC risk, especially in patients with low level viremia $(\mathrm{HBV} \text { DNA }<2000 \mathrm{IU} / \mathrm{mL})^{[9]}$. In this regard, antiviral treatment to decrease the development of HBV-associated HCC mainly focuses on reducing the level of HBV DNA, which is a primary function of NUCs [Table 1]. The second mechanism involves chromosomal instability, whereby part of the HBV genome becomes integrated into the host hepatocyte genome, resulting in host $\mathrm{DNA}^{[10]}$. This mechanism of hepatocarcinogenesis can lead to HBV-associated HCC in patients with CHB who have no cirrhosis. Indeed, patients with occult hepatitis B infection (OBI) still carry the risk of HCC by this mechanism despite a negative serum HBsAg profile ${ }^{[11,12]}$. Therefore, the risk of HCC is not completely eliminated despite remarkable advances in antiviral treatment.

Liver cirrhosis itself is well known as a strong risk factor for HCC, and is characterized by tissue fibrosis and the conversion of normal liver architecture into structurally abnormal nodules ${ }^{[13]}$. If cirrhosis, regardless of etiology, is established, then the risk of HCC remains despite an effective antiviral treatment. Indeed, HBV-related HCC risk reduction by long-term antiviral treatment is more pronounced in patients without cirrhosis ${ }^{[14]}$. Several mechanisms have been postulated that induce hepatocarcinogenesis from cirrhotic liver, including telomere dysfunction, impaired hepatocyte proliferation by loss of replicative competition, and promoting tumor cell proliferation by an altered milieu ${ }^{[15]}$. 


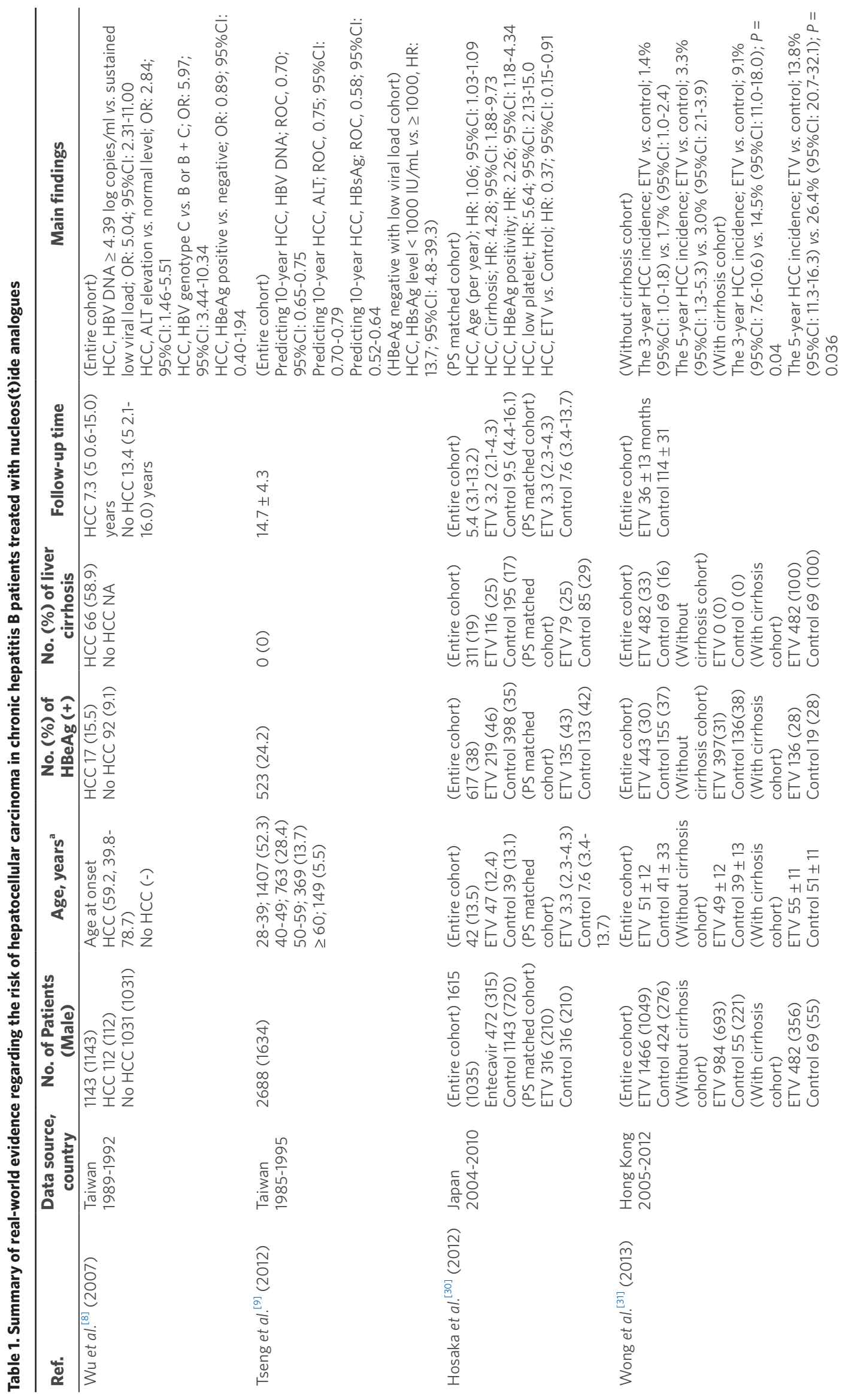



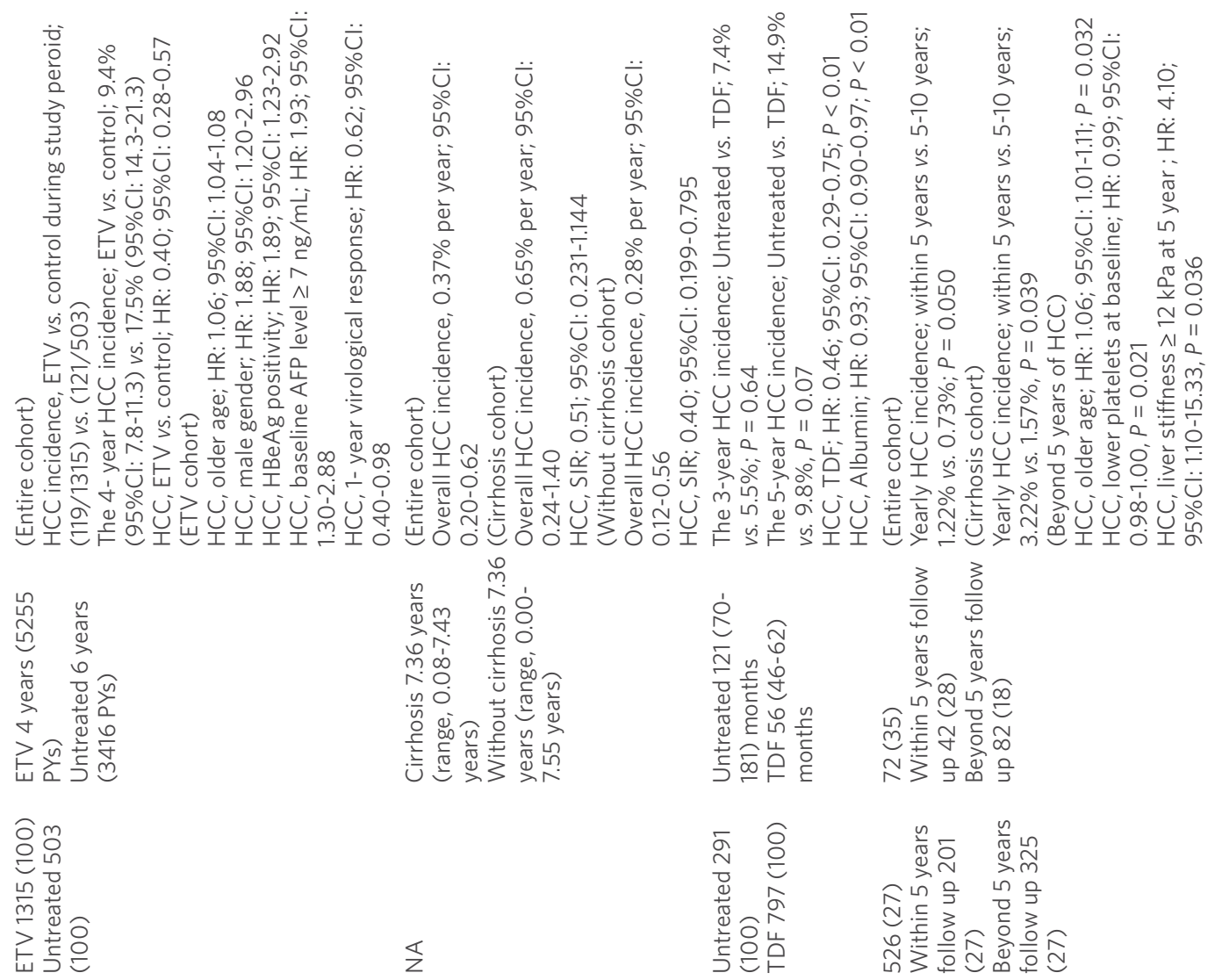

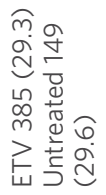

¿
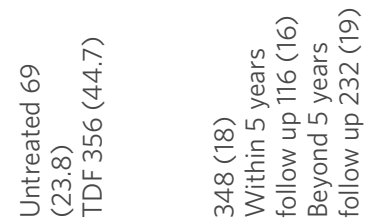

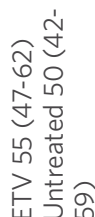

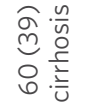

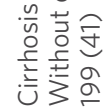

竞离絖

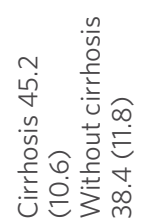

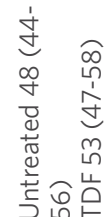

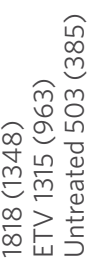

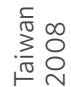

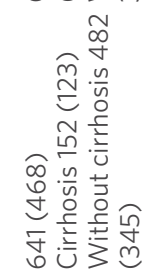

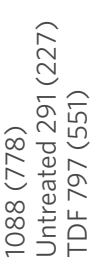

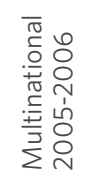

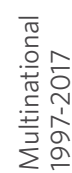

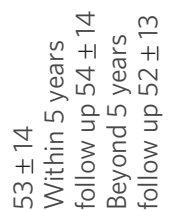

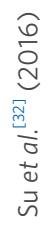

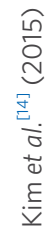

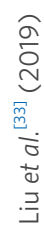

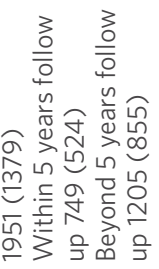

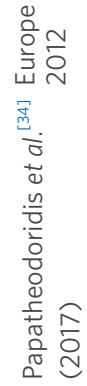



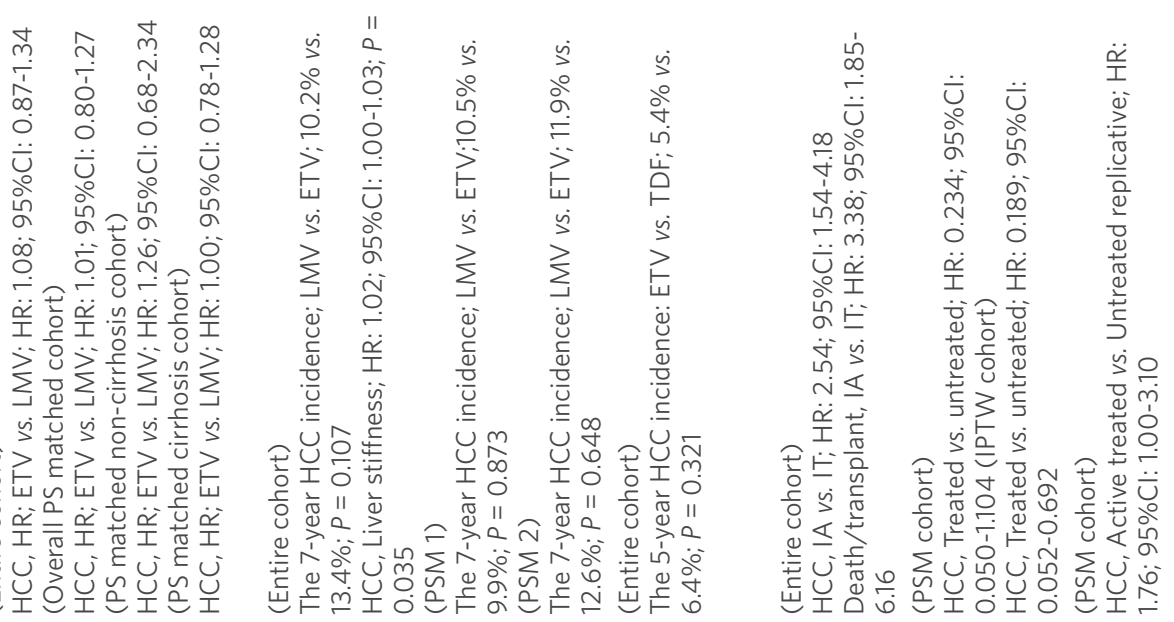

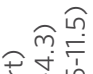

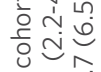

番㐫

焉覀主

$\frac{\pi}{z}$

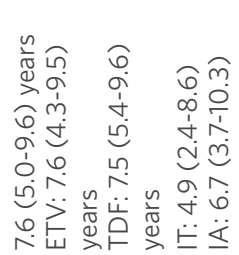

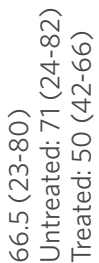

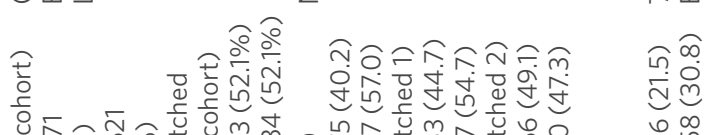

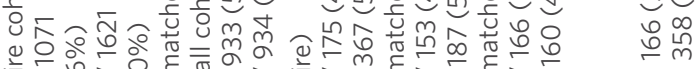

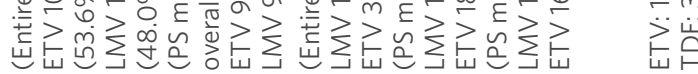

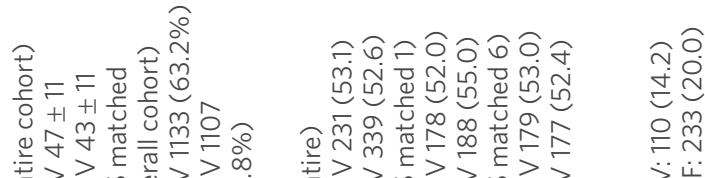

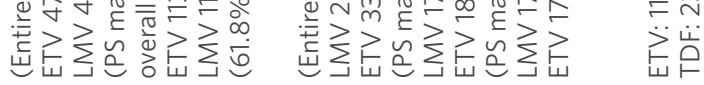

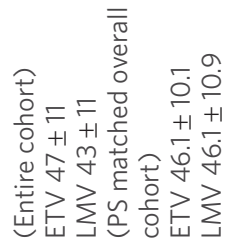

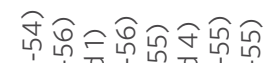

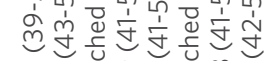

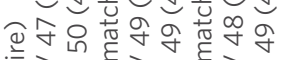

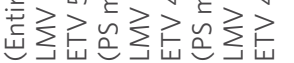

$\pm \stackrel{m}{\mathscr{N}}$

$+1+1$
กิ

는

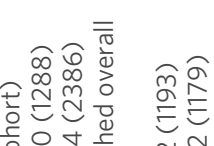

बे

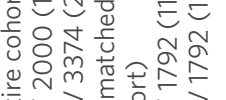

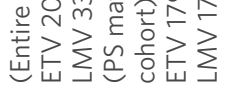

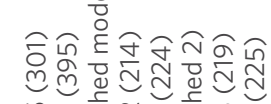

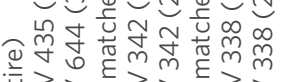

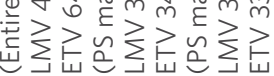

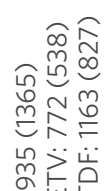

ô

लि

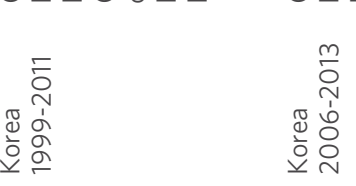

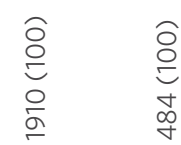

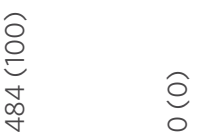

응

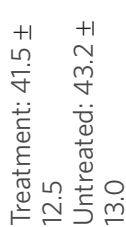

$=$

$\infty$ oㅇ

$\stackrel{m}{\dot{E}}$

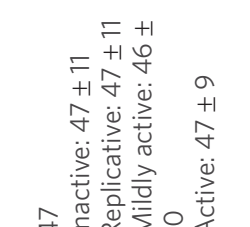

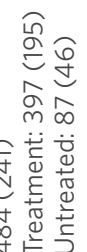

oิ

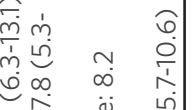

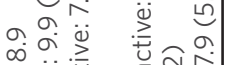

要离离 


\section{CHEMOPREVENTION OF HCC BY INTERFERON AND NUCS}

Currently available antiviral treatments for CHB include interferon- $\alpha$ and NUCs. Interferon has been widely used as an antiviral treatment for many decades until orally available NUCs were introduced. Interferon-based antiviral treatment needs finite duration of treatment resulting in durable host immune control over HBV. Randomized trials and meta-analysis have demonstrated that interferon-based treatment reduces the risk of HCC by $40 \%-50 \%$ in treated compared to untreated patients ${ }^{[16-19]}$. Although interferons reduce the risk of HCC, their detailed usage and mechanisms are beyond the scope of this review. NUCs are an oral antiviral treatment; seven are currently available, namely, lamivudine, adefovir, telbivudine, entecavir (ETV), tenofovir disoproxil fumarate (TDF), tenofovir alafenamide, and besifovir. According to the international treatment guidelines for $\mathrm{CHB}, \mathrm{ETV}$, TDF, and tenofovir alafenamide are equally recommended as the preferred agents for treating $\mathrm{CHB}^{[20-22]}$.

Chemopreventive effects of various NUCs from previous studies are summarized in Table 1. Lamivudine, the first available NUC, showed a protective effect against HCC development in a randomized study with a hazard ratio (HR) of $0.49^{[23]}$. This study is the only randomized, placebo-controlled trial comparing HCC prevention by an NUC and a placebo. Subsequent studies also show that lamivudine significantly reduces the risk of $\mathrm{HCC}$ in patients with $\mathrm{CHB}^{[24-26]}$. Two meta-analyses have indicated that treatment with NUCs reduced the risk of HBV-associated HCC by $74 \%-78 \%$ compared with treatment without NUCs ${ }^{[27,28]}$. However, the risk of HCC remained higher in patients with resistance-related virological breakthrough than in those with sustained virological response ${ }^{[29]}$, implying that sustained and uncontrolled HBV replication may not reduce the risk of HCC, even under NUC treatment.

Compared with the older generation of NUCs that includes lamivudine, adefovir, and telbivudine, ETV shows greater efficacy because it has a higher genetic barrier to viral resistance. Thus, ETV has begun to replace the old generation of NUCs among patients with resistant HBV and is recommended as a firstline antiviral treatment by the international guidelines since late 2000. A propensity score (PS)-matching study from Japan reported that patients with CHB who were treated with ETV showed a lower risk of 5 -year cumulative HCC $(3.7 \%)$ than an untreated historical cohort $(13.7 \% ; P<0.001)^{[30]}$. In a cohort study involving 1980 patients with cirrhosis, treatment with ETV reduced the risk of HCC compared with controls $(\mathrm{HR}=0.55)^{[31]}$. A Taiwanese multicenter study found that ETV treatment in patients with cirrhosis was associated with a $60 \%$ reduction in HCC risk compared with a cirrhotic control group ${ }^{[32]}$. TDF has been widely available since early 2010. In a simulation study, TDF was associated with a reduced incidence of HCC in patients without cirrhosis compared with untreated patients, showing a $60 \%$ reduction after 5 years of TDF treatment ${ }^{[14]}$. A multicenter international retrospective study also revealed that 5 years of TDF treatment reduced the risk of HCC in patients with CHB who had cirrhosis, compared with untreated patients ${ }^{[33]}$. A long-term follow-up study of Caucasian patients with CHB reported that treatment using either ETV or TDF significantly reduced the risk of $\mathrm{HCC}^{[34]}$. A recent meta-analysis involving 23 observational studies with 59,201 patients in the immune-active phase of infection showed that antiviral treatment decreased the risk of HCC compared with controls, with a HR of 0.5. The same study also analyzed 10 observational studies involving patients with cirrhosis and found that antiviral treatment reduced the risk of HCC, with a HR of $0.6^{[35]}$.

\section{CONTROVERSIES OVER THE EFFICACY OF HCC RISK REDUCTION AMONG NUC TYPES}

Although ETV shows better efficacy in suppressing HBV DNA than old-generation NUCs, the HCC risk reduction is poorer than expected. The aforementioned Japanese study revealed that ETV treatment is associated with a significantly lower risk of HCC than treatment with lamivudine $(P=0.043)^{[30]}$. However, a large-scale retrospective study of 5,374 patients with CHB treated using either ETV or lamivudine demonstrated that ETV treatment conferred no lower risk of HCC than lamivudine $(\mathrm{HR}=1.08, P=0.48)^{[36]}$. 
Another retrospective study used PS-matching analysis and showed similar risk for HCC between the two $\operatorname{NUCs}^{[37]}$.

A nationwide Korean cohort study by our group reported that patients with $\mathrm{CHB}$ who were treated using TDF had a significantly lower risk of HCC than those treated with $\mathrm{ETV}^{[38]}$. Many subsequent studies reported controversial findings ${ }^{[39-43]}$. A large-scale cohort study of 29,350 patients with CHB from Hong Kong demonstrated that TDF was associated with a lower risk of HCC than ETV, which was consistent with the nationwide Korean cohort study ${ }^{[40]}$. In contrast, a multicenter retrospective study from Korea showed no difference in the risk of HCC between these two NUCs ${ }^{[41]}$, and a multinational study also failed to show any significant difference in risk of HCC between ETV and TDF ${ }^{[42]}$. Recently, our group conducted a meta-analysis comparing the preventive effect against HCC between these two NUCs ${ }^{[44]}$. We included 15 studies comprising 61,787 patients with CHB who were treated using either ETV or TDF. The results suggested that TDF was associated with a significantly lower risk of HCC than ETV (HR $=0.80, P$ $=0.003)^{[44]}$. Even meta-analyses have presented controversial findings, depending on the characteristics of the included studies, ethnicity, and inclusion of decompensated cirrhosis ${ }^{[45-48]}$. Notably, our group recently used PS-matching to demonstrate that TDF was associated with significantly higher recurrence-free and overall survival rates than ETV in patients who had undergone curative-intent hepatectomy for HBVassociated $\mathrm{HCC}^{[49]}$. Collectively, most studies have either revealed that there is no difference in risk between the two treatments, or that TDF is associated with a lower risk of $\mathrm{HCC}^{[50]}$. No studies have favored ETV treatment over TDF in regards to HCC risk reduction. This controversy will likely remain unresolved until a randomized controlled trial is performed. However, it is unlikely that any such trial will be carried out, because HCC has a low occurrence, and any plausible trial would require a long-term observational period and a large number of patients ${ }^{[50]}$.

\section{ADHERENCE AND DURATION OF TREATMENT INFLUENCE NUC'S CHEMOPREVENTIVE EFFECTS}

Other factors affecting HCC prevention by NUCs include treatment adherence and duration. A study of 894 patients with CHB who were treated with ETV reported that poor adherence, defined as $<90 \%$ compliance, was associated with a higher mortality and greater risk of HCC, particularly among patients with cirrhosis ${ }^{[51]}$. Interestingly, the same group also reported that low levels of HBV DNA, despite the ETV treatment, were not predictive of HCC if patients showed good adherence to ETV treatment. This result emphasized the importance of drug compliance ${ }^{[52]}$. A nationwide Korean cohort study indicated that the incidence of HCC was incremental in a dose-dependent manner among poor-, intermediate-, and goodadherence groups, although the difference was not significant after multivariable adjustments ${ }^{[53]}$.

The treatment duration of NUCs for chemoprevention of HCC follows the treatment guidelines of $\mathrm{CHB}^{[20-22]}$. Currently, the realistic goal of CHB treatment is a so-called "functional cure", defined as the loss of HBsAg, regardless of HBsAb appearance. Therefore, once NUCs are started, treatment should be continued until this goal is achieved, even though controversies exist. A retrospective study involving 1,951 Caucasian patients with CHB demonstrated that the risk of HCC decreased after the first 5 years of ETV or TDF treatment ${ }^{[34]}$. However, a Korean retrospective study showed that the incidence of HCC did not significantly differ before and after 5 years of ETV treatment, suggesting that the lon-term risk of HCC in Asian patients with $\mathrm{CHB}$ may continue to persist ${ }^{[54]}$. This issue should be further validated and different NUCs must be compared to infer more conclusively.

\section{WHO SHOULD BE TREATED WITH NUCS TO REDUCE THE RISK OF HCC?}

The natural course of $\mathrm{CHB}$ is generally classified into four different phases based on serum HBV replicative status, with serum alanine aminotransferase (ALT) level used as a surrogate marker for significant liver 
inflammation. These phases include immune-tolerant, immune-active, inactive carrier, and hepatitis $B$ e-antigen (HBeAg)-negative hepatitis. Current international treatment guidelines for CHB universally recommend antiviral treatment in patients with immune-active phase or HbeAg-negative hepatitis ${ }^{[20-22]}$. Moreover, patients with cirrhosis are advised to initiate antiviral treatment, regardless of serum HBV DNA level ${ }^{[20-22]}$. Most patients with $\mathrm{CHB}$ at a given time can be classified into one phase of the natural $\mathrm{CHB}$ course. However, $\mathrm{CHB}$ is a dynamic disease that interacts with $\mathrm{HBV}$ and host immunity. Hence, the phases of $\mathrm{CHB}$ change based on patient age, immunity, and viral replication status. In practice, a few patients with $\mathrm{CHB}$, especially those without cirrhosis, reside in the so called "gray zone", which is not addressed in treatment guidelines. Current international treatment guidelines state that NUC should be initiated based on two main factors: serum HBV DNA and ALT level. Without evidence of cirrhosis, NUC should be started if the serum HBV DNA level is high $(\geq 20,000 \mathrm{IU} / \mathrm{mL}$ for $\mathrm{HBeAg}$-positive patients and $\geq 2,000 \mathrm{IU} / \mathrm{mL}$ for HBeAg-negative patients) or if ALT levels are abnormal [ $2 \times$ the upper limit of normal (ULN)]. However, current treatment criteria leave several unresolved questions. Specifically, are patients with $\mathrm{CHB}$ who do not meet the treatment initiation criteria definitely safe from developing HCC without the antiviral treatment? Current treatment initiation criteria stipulate that elevated serum ALT can be used as a surrogate marker of active liver inflammation because liver biopsy is not generally conducted for this purpose. However, mounting evidence indicates that serum ALT levels may not be a good criterion for deciding the initiation of antiviral treatment because it is altered under other non-HBV conditions, such as combined fatty liver disease and heavy alcohol assumption. In addition, previous studies have shown a poor association between serum ALT levels and the degree of necroinflammation in the hepatocytes of biopsied specimens, especially when serum ALT level is only slightly elevated (ALT $<2 \times$ ULN $)^{[55,56]}$. In other words, the current treatment initiation criteria may delay antiviral treatment until significant active liver disease becomes apparent. This assumes that HBV infection is basically harmless in HBV carriers until many decades have passed and only when active liver disease is present ${ }^{[57]}$. Traditionally, the immune-tolerant phase refers to the immunologically and histologically dormant stage not requiring antiviral treatment, according to the treatment guidelines. In this regard, recent immunological studies have revealed that patients in the immune-tolerant and immune-active phases show a similar HBVspecific T-cell response, indicating that the immune-tolerant phase should not be considered completely benign, as previously assumed ${ }^{[58]}$. Another study suggested that hepatocarcinogenic processes, such as HBV DNA integration and clonal hepatocyte expansion, were already present during the early phase of CHB, whereas traditional concepts understand the immune-tolerant phase as benign ${ }^{[59]}$. Indeed, these in vitro studies were supported by RWE. A large-scale retrospective study from Korea demonstrated that untreated patients in the immune-tolerant phase had a higher risk of HCC than treated immune-active patients ${ }^{[60]}$. Another multicenter retrospective study from Korea showed that NUC treatment of patients currently in the immune-tolerant phase reduces the risk of HCC, even if the serum ALT level is below the upper limit of normal ${ }^{[61]}$. Another gray zone includes patients who are HBeAg-negative and have a high viral load, but have normal or slightly above normal ALT levels. As mentioned above, current treatment guidelines allow treatment initiation if the serum ALT level is more than $2 \times$ ULN. However, a retrospective study suggested that untreated $\mathrm{HBeAg}$-negative, high viral-load patients without significant ALT elevation carried a higher risk of HCC than treated active phase patients with elevated serum $\mathrm{ALT}^{[62]}$. The degree of liver fibrosis resulting from hepatocyte injury by necroinflammation is also associated with the development of HCC. To measure the degree of liver fibrosis, liver biopsy has traditionally been used. However, the clinical utility of liver biopsy is limited by its invasiveness, sampling variability, and inter-observer variability. Therefore, several non-invasive tests of fibrosis have been developed and validated ${ }^{[63-65]}$. These non-invasive assessments of liver fibrosis can aid the treatment decision-making process if a patient does not meet the traditional treatment criteria. Indeed, international guidelines recommend treatment initiation in patients with significant fibrosis by non-invasive assessments ${ }^{[20-22]}$. Liver biopsy should be preserved in selected cases where serologic and non-invasive tests are inconclusive in determining the disease activity. In addition, 
patients with first-degree family history of HCC, extrahepatic manifestations, or age $>40$ years may be considered for treatments with antiviral agents considering their increased risk of $\mathrm{HCC}^{[66]}$.

Taken together, to prevent HBV-related HCC by using appropriate and timely antiviral treatment, the current treatment initiation criteria might be inadequate and could be expanded based on serum HBV DNA and ALT levels, degree of liver fibrosis, and personal characteristics ${ }^{[57]}$. Lastly, antiviral treatment is not recommended for patients with OBI by current international guidelines. Unlike overt HBV infection, patients with OBI are HBsAg negate but may have intermittent very low level of serum HBV DNA ${ }^{[1,12]}$. Indeed, patients with OBI still carry the risk of HCC and the risk of HCC may increase with combined known liver diseases such as chronic HCV infection. However, this area should be further investigated by future studies.

\section{OTHER CONSIDERATIONS WITH NUC TREATMENT TO REDUCE HCC RISK}

Many preventive interventions have been carried out in patients with CHB to lower the risk of HCC development, such as lifestyle modification and correct dietary habits ${ }^{[67]}$.

\section{Alcohol}

Alcohol consumption is an independent risk factor for HCC, and when patients with CHB drink alcohol, poorer outcomes are expected. The mechanisms of how alcohol interacts with HBV are not fully demonstrated, but it may accelerate viral replication, causing oxidative stress, or hinder the immune system $^{[68]}$. Heavy alcohol consumption increases HCC risk significantly. A retrospective study in Taiwan compared alcoholic patients with $\mathrm{CHB}$, non-alcoholic patients with $\mathrm{CHB}$, and alcoholic patients. The results of a 10-year cumulative HCC incidence in these groups were $52.8 \%, 39.8 \%$, and $25.6 \%$, respectively $(P<0.001)^{[69]}$. In addition, alcohol consumption negatively affects the protective effect of NUCs on HCC. Cumulative alcohol consumption of more than $200 \mathrm{~kg}$ for a lifetime was posed as an independent risk factor for HCC in NUC-treated patients with $\mathrm{CHB}(\mathrm{HR}=2.21, P=0.013)^{[30]}$.

\section{Smoking}

Smoking also confers an increased risk of HCC. According to a study in a European cohort, smoking, even former smoking, was highly related to HCC occurrence in patients with chronic viral hepatitis [former smoking, odds ratio (OR): 1.98, $P=0.092$; current smoking, OR: 4.55, $P=0.001]^{[70]}$. Smoking also increases the risk of HCC-related mortality. Subjects who were free of malignancy were followed up until the end of the study period or death from HCC. The relative risk of HCC-related mortality was 1.4 in men and 1.1 in women ${ }^{[71]}$.

\section{Metabolic syndrome}

Fatty liver disease a crucial factor in HCC. Non-alcoholic fatty liver disease (NAFLD) is closely associated with diabetes, hyperlipidemia, and obesity. Diabetes is also associated with a two-fold increased risk of $\mathrm{HCC}^{[72]}$. Obese patients with $\mathrm{CHB}$ are more likely to have HCC. A prospective study was carried out in Taiwan in which 2,903 HBsAg-positive male patients were followed up for 14.7 years ${ }^{[73]}$. As body mass index (BMI) increased, so did the risk of HCC. Compared with normal-weighted patients (BMI = 18.5-24.9 $\left.\mathrm{kg} / \mathrm{m}^{2}\right)$, overweight patients $\left(\mathrm{BMI}=25.0-29.9 \mathrm{~kg} / \mathrm{m}^{2}\right)$ and obese patients $\left(\mathrm{BMI}>30.0 \mathrm{~kg} / \mathrm{m}^{2}\right)$ were more likely to be suffering from HCC or liver-related death, with HRs of 1.48 and 1.96 , respectively ${ }^{[73]}$. To date, a specific diet affecting the clinical course of CHB is not identified. However, lifestyle modification with a healthy diet and proper exercise is important.

\section{CONCLUSION}

Recently, dramatic advancements have been made in HBV treatment; the development of an HBV vaccine and antiviral agents against $\mathrm{HBV}$ have tremendously improved clinical outcomes, including viral 
hepatitis and its fatal complications. Nevertheless, given the enormous clinical and socio-economical burdens of HCC caused by HBV, CHB should be properly managed with appropriate and timely use of antiviral treatments for secondary prevention. Unfortunately, no current drug can eliminate HBV nor can it completely eliminate the risk of HCC. However, many recent RWEs have provided important insights into secondary prevention of HCC, making clinicians reconsider the indications for antiviral treatment beyond the current treatment guidelines set forth for patients with CHB. Clinicians should be aware of the limitations of RWE before applying it in research, but the method may be used across a wide spectrum of $\mathrm{CHB}$ research through judicious selection of data sources, refinement of study designs, and appropriate analytic approaches. This will bring researchers a step closer to optimizing the secondary prevention of HCC in patients with CHB.

\section{DECLARATIONS}

\section{Authors' contributions}

Responsible for the conception, review, drafting, and critical revision of the manuscript, and approved the final version of the manuscript: Lim J, Choi J

\section{Availability of data and materials}

Not available.

\section{Financial support and sponsorship}

There was no funding or support from industry for this study. The interpretation and reporting of the data were the sole responsibility of the authors.

\section{Conflicts of interest}

Both authors declared that there are no conflicts of interest.

\section{Ethical approval and consent to participate}

Not applicable.

\section{Consent for publication}

Not applicable.

\section{Copyright}

(c) The Author(s) 2021.

\section{REFERENCES}

1. Blach S, Zeuzem S, Manns M, et al. Global prevalence and genotype distribution of hepatitis C virus infection in 2015: a modelling study. Lancet Gastroenterol Hepatol 2017;2:161-76.

2. Mak LY, Cruz-Ramón V, Chinchilla-López P, et al. Global Epidemiology, Prevention, and Management of Hepatocellular Carcinoma. Am Soc Clin Oncol Educ Book 2018;38:262-79.

3. El-Serag HB. Epidemiology of viral hepatitis and hepatocellular carcinoma. Gastroenterology 2012;142:1264-73.e1.

4. Bertuccio P, Turati F, Carioli G, et al. Global trends and predictions in hepatocellular carcinoma mortality. J Hepatol 2017;67:302-9.

5. Sayiner M, Golabi P, Younossi ZM. Disease Burden of Hepatocellular Carcinoma: A Global Perspective. Dig Dis Sci 2019;64:910-7.

6. Block TM, Mehta AS, Fimmel CJ, Jordan R. Molecular viral oncology of hepatocellular carcinoma. Oncogene 2003;22:5093-107.

7. Chen CJ, Yang HI, Su J, et al; REVEAL-HBV Study Group. Risk of hepatocellular carcinoma across a biological gradient of serum hepatitis B virus DNA level. JAMA 2006;295:65-73.

8. Wu CF, Yu MW, Lin CL, et al. Long-term tracking of hepatitis B viral load and the relationship with risk for hepatocellular carcinoma in men. Carcinogenesis 2008;29:106-12.

9. Tseng TC, Liu CJ, Yang HC, et al. High levels of hepatitis B surface antigen increase risk of hepatocellular carcinoma in patients with low HBV load. Gastroenterology 2012;142:1140-9.e3; quiz e13-4. 
10. Murakami Y, Saigo K, Takashima H, et al. Large scaled analysis of hepatitis B virus (HBV) DNA integration in HBV related hepatocellular carcinomas. Gut 2005;54:1162-8.

11. Mak LY, Wong DK, Pollicino T, Raimondo G, Hollinger FB, Yuen MF. Occult hepatitis B infection and hepatocellular carcinoma: Epidemiology, virology, hepatocarcinogenesis and clinical significance. J Hepatol 2020;73:952-64.

12. Raimondo G, Locarnini S, Pollicino T, Levrero M, Zoulim F, Lok AS; Taormina Workshop on Occult HBV Infection Faculty Members. Update of the statements on biology and clinical impact of occult hepatitis B virus infection. J Hepatol 2019;71:397-408.

13. Pinzani M, Rosselli M, Zuckermann M. Liver cirrhosis. Best Pract Res Clin Gastroenterol 2011;25:281-90.

14. Kim WR, Loomba R, Berg T, et al. Impact of long-term tenofovir disoproxil fumarate on incidence of hepatocellular carcinoma in patients with chronic hepatitis B. Cancer 2015;121:3631-8.

15. El-Serag HB, Rudolph KL. Hepatocellular carcinoma: epidemiology and molecular carcinogenesis. Gastroenterology 2007;132:2557-76.

16. Lin SM, Sheen IS, Chien RN, Chu CM, Liaw YF. Long-term beneficial effect of interferon therapy in patients with chronic hepatitis B virus infection. Hepatology 1999;29:971-5.

17. Wong GL, Yiu KK, Wong VW, Tsoi KK, Chan HL. Meta-analysis: reduction in hepatic events following interferon-alfa therapy of chronic hepatitis B. Aliment Pharmacol Ther 2010;32:1059-68.

18. Yang YF, Zhao W, Zhong YD, Xia HM, Shen L, Zhang N. Interferon therapy in chronic hepatitis B reduces progression to cirrhosis and hepatocellular carcinoma: a meta-analysis. J Viral Hepat 2009;16:265-71.

19. Lin SM, Yu ML, Lee CM, et al. Interferon therapy in HBeAg positive chronic hepatitis reduces progression to cirrhosis and hepatocellular carcinoma. J Hepatol 2007;46:45-52.

20. Terrault NA, Lok ASF, McMahon BJ, et al. Update on prevention, diagnosis, and treatment of chronic hepatitis B: AASLD 2018 hepatitis B guidance. Hepatology 2018;67:1560-99.

21. Sarin SK, Kumar M, Lau GK, et al. Asian-Pacific clinical practice guidelines on the management of hepatitis B: a 2015 update. Hepatol Int 2016;10:1-98.

22. European Association for the Study of the Liver. Electronic address: easloffice@easloffice.eu., European Association for the Study of the Liver. EASL 2017 Clinical Practice Guidelines on the management of hepatitis B virus infection. J Hepatol 2017;67:370-98.

23. Liaw YF, Sung JJ, Chow WC, et al; Cirrhosis Asian Lamivudine Multicentre Study Group. Lamivudine for patients with chronic hepatitis B and advanced liver disease. N Engl J Med 2004;351:1521-31.

24. Papatheodoridis GV, Dimou E, Dimakopoulos K, et al. Outcome of hepatitis B e antigen-negative chronic hepatitis B on long-term nucleos(t)ide analog therapy starting with lamivudine. Hepatology 2005;42:121-9.

25. Yuen MF, Seto WK, Chow DH, Tsui K, Wong DK, et al. Long-term lamivudine therapy reduces the risk of long-term complications of chronic hepatitis B infection even in patients without advanced disease. Antivir Ther 2007;12:1295-303.

26. Matsumoto A, Tanaka E, Rokuhara A, et al; Inuyama Hepatitis Study Group. Efficacy of lamivudine for preventing hepatocellular carcinoma in chronic hepatitis B: A multicenter retrospective study of 2795 patients. Hepatol Res 2005;32:173-84.

27. Sung JJ, Tsoi KK, Wong VW, Li KC, Chan HL. Meta-analysis: Treatment of hepatitis B infection reduces risk of hepatocellular carcinoma. Aliment Pharmacol Ther 2008;28:1067-77.

28. Zhang QQ, An X, Liu YH, et al. Long-term nucleos(t)ide analogues therapy for adults with chronic hepatitis B reduces the risk of longterm complications: a meta-analysis. Virol J 2011;8:72.

29. Liaw YF. Impact of therapy on the long-term outcome of chronic hepatitis B. Clin Liver Dis 2013;17:413-23.

30. Hosaka T, Suzuki F, Kobayashi M, et al. Long-term entecavir treatment reduces hepatocellular carcinoma incidence in patients with hepatitis B virus infection. Hepatology 2013;58:98-107.

31. Wong GL, Chan HL, Mak CW, et al. Entecavir treatment reduces hepatic events and deaths in chronic hepatitis B patients with liver cirrhosis. Hepatology 2013;58:1537-47.

32. Su TH, Hu TH, Chen CY, et al; C-TEAM study group and the Taiwan Liver Diseases Consortium. Four-year entecavir therapy reduces hepatocellular carcinoma, cirrhotic events and mortality in chronic hepatitis B patients. Liver Int 2016;36:1755-64.

33. Liu K, Choi J, Le A, et al. Tenofovir disoproxil fumarate reduces hepatocellular carcinoma, decompensation and death in chronic hepatitis B patients with cirrhosis. Aliment Pharmacol Ther 2019;50:1037-48.

34. Papatheodoridis GV, Idilman R, Dalekos GN, et al. The risk of hepatocellular carcinoma decreases after the first 5 years of entecavir or tenofovir in Caucasians with chronic hepatitis B. Hepatology 2017;66:1444-53.

35. Lok AS, McMahon BJ, Brown RS Jr, et al. Antiviral therapy for chronic hepatitis B viral infection in adults: A systematic review and meta-analysis. Hepatology 2016;63:284-306.

36. Lim YS, Han S, Heo NY, Shim JH, Lee HC, Suh DJ. Mortality, liver transplantation, and hepatocellular carcinoma among patients with chronic hepatitis B treated with entecavir vs lamivudine. Gastroenterology 2014;147:152-61.

37. Kim HS, Kim BK, Kim SU, et al. Association Between Level of Fibrosis, Rather Than Antiviral Regimen, and Outcomes of Patients With Chronic Hepatitis B. Clin Gastroenterol Hepatol 2016;14:1647-56.e6.

38. Choi J, Kim HJ, Lee J, Cho S, Ko MJ, Lim YS. Risk of Hepatocellular Carcinoma in Patients Treated With Entecavir vs Tenofovir for Chronic Hepatitis B: A Korean Nationwide Cohort Study. JAMA Oncol 2019;5:30-6.

39. Oh H, Yoon EL, Jun DW, Ahn SB, Lee H-Y, et al. No difference in incidence of hepatocellular carcinoma in patients with chronic HBV infection treated with entecavir vs tenofovir. Clin Gastroenterol Hepatol 2020;18:2793-802.e6.

40. Yip TC, Wong VW, Chan HL, Tse YK, Lui GC, Wong GL. Tenofovir is associated with lower risk of hepatocellular carcinoma than entecavir in patients with chronic HBV infection in China. Gastroenterology 2020;158:215-25.e6.

41. Kim SU, Seo YS, Lee HA, et al. A multicenter study of entecavir vs. tenofovir on prognosis of treatment-naïve chronic hepatitis B in 
South Korea. J Hepatol 2019;71:456-64.

42. Hsu YC, Wong GL, Chen $\mathrm{CH}$, et al. Tenofovir versus entecavir for hepatocellular carcinoma prevention in an international consortium of chronic hepatitis B. Am J Gastroenterol 2020;115:271-80.

43. Papatheodoridis GV, Dalekos GN, Idilman R, et al. Similar risk of hepatocellular carcinoma during long-term entecavir or tenofovir therapy in Caucasian patients with chronic hepatitis B. J Hepatol 2020;73:1037-45.

44. Choi WM, Choi J, Lim YS. Effects of tenofovir vs entecavir on risk of hepatocellular carcinoma in patients with chronic HBV infection: a systematic review and meta-analysis. Clin Gastroenterol Hepatol 2021;19:246-58.e9.

45. Li M, Lv T, Wu S, et al. Tenofovir versus entecavir in lowering the risk of hepatocellular carcinoma development in patients with chronic hepatitis B: a critical systematic review and meta-analysis. Hepatol Int 2020;14:105-14.

46. Dave S, Park S, Murad MH, et al. Comparative effectiveness of entecavir versus tenofovir for preventing hepatocellular carcinoma in patients with chronic hepatitis B: a systematic review and meta-analysis. Hepatology 2020:68-78.

47. Cheung KS, Mak LY, Liu SH, et al. Entecavir vs tenofovir in hepatocellular carcinoma prevention in chronic hepatitis B infection: a systematic review and meta-analysis. Clin Transl Gastroenterol 2020;11:e0236.

48. Tseng C, Hsu Y, Chen T, et al. Hepatocellular carcinoma incidence with tenofovir versus entecavir in chronic hepatitis B: a systematic review and meta-analysis. Lancet Gastroenterol Hepatol 2020;5:1039-52.

49. Choi J, Jo C, Lim YS. Tenofovir versus entecavir on recurrence of hepatitis B virus-related hepatocellular carcinoma after surgical resection. Hepatology 2020;73:661-73.

50. Choi J, Lim Y-S. Comparison of risk of hepatocellular carcinoma between tenofovir and entecavir: one direction or no direction. $J$ Hepatol 2019;71:846-7.

51. Shin JW, Jung SW, Lee SB, et al. Medication nonadherence increases hepatocellular carcinoma, cirrhotic complications, and mortality in chronic hepatitis B patients treated with entecavir. Am J Gastroenterol 2018;113:998-1008.

52. Lee SB, Jeong J, Park JH, et al. Low-level viremia and cirrhotic complications in patients with chronic hepatitis B according to adherence to entecavir. Clin Mol Hepatol 2020;26:364-75.

53. Lee J, Cho S, Kim HJ, Lee H, Ko MJ, Lim YS. High level of medication adherence is required to lower mortality in patients with chronic hepatitis B taking entecavir: A nationwide cohort study. J Viral Hepat 2021;28:353-63.

54. Kim BG, Park NH, Lee SB, et al. The risk of hepatocellular carcinoma within and beyond the first 5 years of entecavir in Korean patients with chronic hepatitis B. Liver Int 2018;38:2269-76.

55. Nguyen MH, Garcia RT, Trinh HN, et al. Histological disease in Asian-Americans with chronic hepatitis B, high hepatitis B virus DNA, and normal alanine aminotransferase levels. Am J Gastroenterol 2009;104:2206-13.

56. Park JY, Park YN, Kim DY, et al. High prevalence of significant histology in asymptomatic chronic hepatitis B patients with genotype C and high serum HBV DNA levels. J Viral Hepat 2008;15:615-21.

57. Zoulim F, Mason WS. Reasons to consider earlier treatment of chronic HBV infections. Gut 2012;61:333-6.

58. Kennedy PTF, Sandalova E, Jo J, et al. Preserved T-cell function in children and young adults with immune-tolerant chronic hepatitis B. Gastroenterology 2012;143:637-45.

59. Mason WS, Gill US, Litwin S, Zhou Y, Peri S, et al. HBV DNA integration and clonal hepatocyte expansion in chronic hepatitis B patients considered immune tolerant. Gastroenterology 2016;151:986-98. e4.

60. Kim GA, Lim YS, Han S, et al. High risk of hepatocellular carcinoma and death in patients with immune-tolerant-phase chronic hepatitis B. Gut 2018;67:945-52.

61. Chang Y, Choe WH, Sinn DH, et al. Nucleos(t)ide analogue treatment for patients with hepatitis B virus (HBV) e antigen-positive chronic HBV genotype C infection: a Nationwide, multicenter, retrospective study. J Infect Dis 2017;216:1407-14.

62. Choi GH, Kim GA, Choi J, Han S, Lim YS. High risk of clinical events in untreated HBeAg-negative chronic hepatitis B patients with high viral load and no significant ALT elevation. Aliment Pharmacol Ther 2019;50:215-26.

63. Wong GL, Chan HL, Wong CK, et al. Liver stiffness-based optimization of hepatocellular carcinoma risk score in patients with chronic hepatitis B. J Hepatol 2014;60:339-45.

64. Chan AW, Chan RC, Wong GL, et al. New simple prognostic score for primary biliary cirrhosis: Albumin-bilirubin score. $J$ Gastroenterol Hepatol 2015;30:1391-6.

65. Vallet-Pichard A, Mallet V, Nalpas B, et al. FIB-4: an inexpensive and accurate marker of fibrosis in HCV infection. comparison with liver biopsy and fibrotest. Hepatology 2007;46:32-6.

66. Kao JH, Hu TH, Jia J, et al. East Asia expert opinion on treatment initiation for chronic hepatitis B. Aliment Pharmacol Ther 2020;52:1540-50.

67. Fujiwara N, Friedman SL, Goossens N, Hoshida Y. Risk factors and prevention of hepatocellular carcinoma in the era of precision medicine. J Hepatol 2018;68:526-49.

68. Iida-Ueno A, Enomoto M, Tamori A, Kawada N. Hepatitis B virus infection and alcohol consumption. World J Gastroenterol 2017;23:2651-9.

69. Lin CW, Lin CC, Mo LR, et al. Heavy alcohol consumption increases the incidence of hepatocellular carcinoma in hepatitis B virusrelated cirrhosis. J Hepatol 2013;58:730-5.

70. Trichopoulos D, Bamia C, Lagiou P, et al. Hepatocellular carcinoma risk factors and disease burden in a European cohort: a nested casecontrol study. J Natl Cancer Inst 2011;103:1686-95.

71. Jee SH, Ohrr H, Sull JW, Samet JM. Cigarette smoking, alcohol drinking, hepatitis B, and risk for hepatocellular carcinoma in Korea. $J$ Natl Cancer Inst 2004;96:1851-6. 
72. Chen HF, Chen P, Li CY. Risk of malignant neoplasms of liver and biliary tract in diabetic patients with different age and sex stratifications. Hepatology 2010;52:155-63.

73. Yu MW, Shih WL, Lin CL, et al. Body-mass index and progression of hepatitis B: a population-based cohort study in men. J Clin Oncol 2008;26:5576-82. 